\title{
Discurso del Sr. Raúl Prebisch en la Reunión de Gobernadores del BID, en Abrild de 1970, celebrada en Punta del Este
}

En el mes de Abril de 1970, en Punta del Este, Uruguay, turo luggar la XI Reunión de la Asamblea de Gobernadores del Banco Interamericano de Desarrollo.

Un año antes, el Presidente del Banco, nuestro compatriota, señor Felipe Horrera Lane -Profesor del Departamento de Derecho Zconómico- habia invítado al ex-Secretario rjecutivo de la CEPAL, sefior Raul Prebisch a preparar un informe sobre el estado del subdesarrollo en América Latina.

Hallándose listo el informe del señor Prebisch, se invitó al prestigioso economista argentino a la Junta de Gobernadores de Punta del Este para que presentara en forma ofictal el referido documento.

Fue asi, como en sesión especial celebrada el 23 de Abril, don Raul Preblech hizo entrega de su informe mediante un discurso que representa el miry particular enfoque de su autor respecto del grado de subdesarrollo que vive muestro continente.

Reproducimos este discurso por una especial deferencia del Profesor Francisco A. Pinto, quien asistio a dicha cita interamericana. 


\section{Discurso del Sr. Raúl Prebisch en la Sesión}

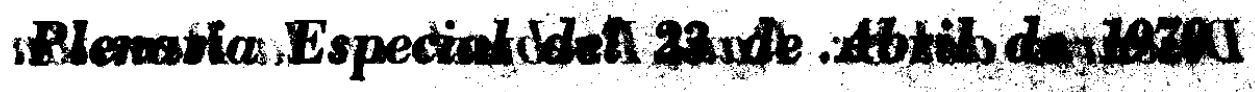

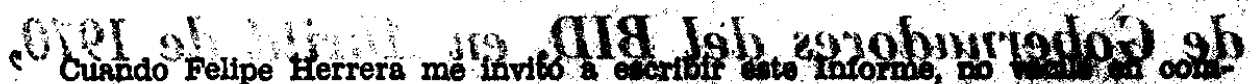

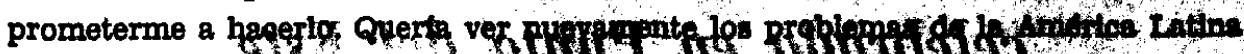

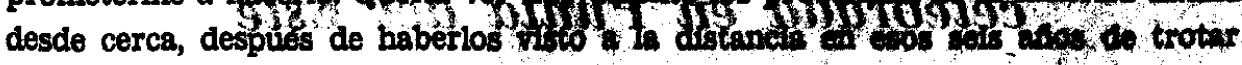
por los mundos. Más aún, después do haber visitado un gran noimero de parpas

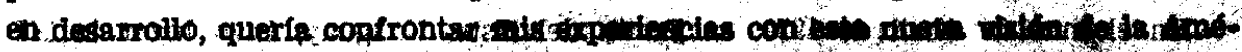

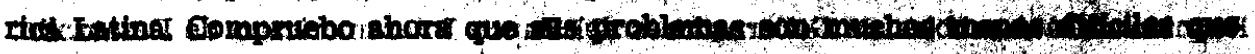

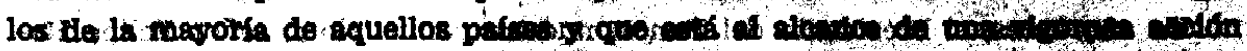

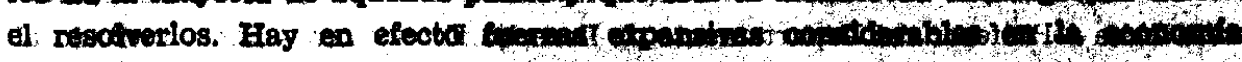

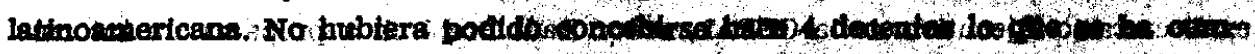

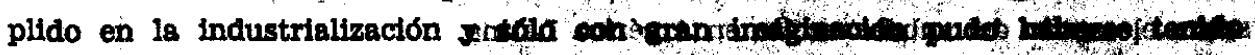

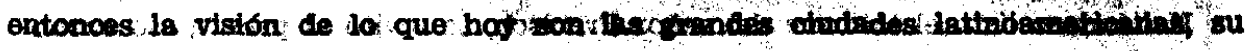

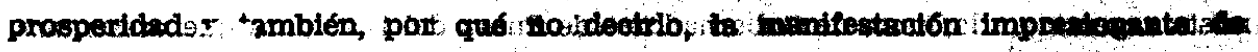

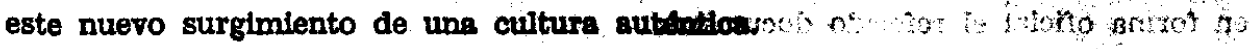

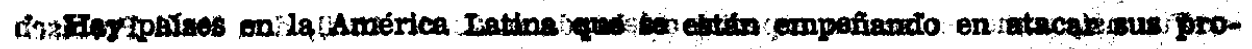

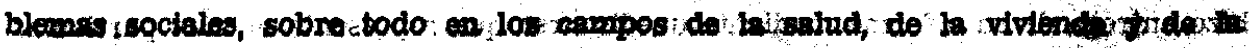

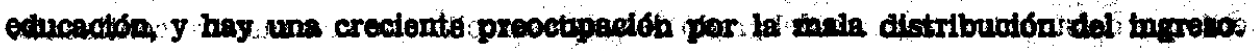

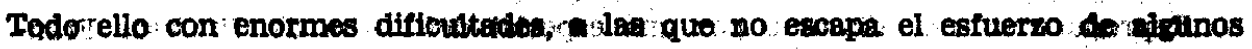

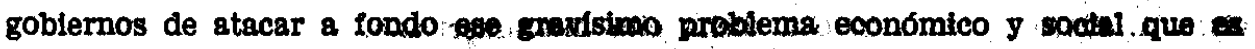
la inflación. Muy diffcil hacerlo por clerto, muy difficil sofocar sus rafces profundas mientras no se acelere el ritmo del desarrollo.

Por ello no existe ni en mi informe ni en esta presentación el ánimo de lenorar las enormes dificultades que encierran estos problemas y los sacrificios que se realizan para resolverlos. Tampoco se desconocen, y parecería innecesario decirio, las diferencias considerables que existen entre los países latinoamericanos. Ia varieriad de niveles de desarrollo y grados de inđustrialización, la diferente dotación de recursos naturales, la dimensión y condiciones de sus mercacios internos, en fin, las singularidades propias de cada unidad nacional.

Muchas veces, sin embargo, los problemas inmediatos enfocados en el marco estrecho de cada país oscurecen la perspectiva de largo alcance y esto entorpece insertar la dificil acción cotidiana en una estrategia de desarrollo de largo plaso.

De suyo difficil esta tarea de la transformación y el desarrollo de nuestros países. La lucha es dura, y debe serio. Y más aún cuando al realizarla existe el tenaz empefio por preservar clertos valores fundamentales que es necesarlo afianzar y extender. 
Actúan en América Latina poderosas fuerzas expansivas que constituyen nuestro mayor potencial del desarrollo. ¿Por qué entonces tanta preocupación, por qué no dejar seguir el curso de los acontecimientos? Si mi respuesta hubiera sido positiva, no hubiera escrito este Informe. Desgraciadamente tiene la América Latina muy graves problemas, pues esas fuerzas expansivas están seriamente limitadas por factores externos e internos.

No podría decirse que el ritmo de desarrollo de algo más de $5 \%$ anual que ha tenido la América Latina en los últimos veinte años sea una tasa pequeña, pero el ritmo de desarrollo no puede medirse en si mismo, sino por lo que significa detde el punto de vista económico y social. Y desde este punto de vista el ritmo latinoamericano no ha podido resolver lo que llamo la insuficiencia dínámica de la . economía.

¿Por qué Insuficiencia dinámica? Fundamentalmente porque el sistema económico, tal cual ha venido funcionando, no ha demostrado aptitud para absorber productivamente sino una fracción del incremento extraordinario de la fuerza de trabajo, resultado de la elevada tasa de crecimiento de la población.

Queda mucha gente redundante en los campos, a pesar de la precaria técnica agrícola prevaleciente, $y$ la gente que sale de la agricultura solo en minima parte es absorbida productivamente por la industria, la construcción y la mineria, que llamo en mi informe el grupo de la Industria. El resto va a abultar la ocupación en una vasta gama de servicios, cuando no queda desocupada. Se trata de una absorción espúrea y no genuina de fuerza de trabajo, que gravita muy adversamento sobre toda la economía.

Anteayer Felipe Herrera se refería al problema de la concentración urbana. Esta concentración patoíógica de gente en las ciudades que es en parte consecuencia de las grandes fallas con que está funcionando el sistema económico en la América Latina.

Me he preocupado en mi Informe de medir este fenómeno de la fuerza de trabajo y las cifras son realmente impresionantes. Hace 20 años el $35 \%$ de la fuerza de trabajo fuera de la agricultura, principalmente en las ciudades, trabajaba en el grupo de la Industria. Esta proporción debió haber subido, pero por el contrario es ahora del $30 \%$. Solamente dos paises de la América Latina se sustraen a esta seria deformación en la estructura ocupacional de la fuerza de trabajo, Méxtco y Argentina, en donde el grupo de la Industria absorbe el $40 \%$ de la fuerza de trabajo no agrícola. Pero México tiene fuerte redundancia de gente en la agricultura y la Argentina si bien tiene una proporción relativamente baja de fuerza de trabajo en esta actividad no escapa a la redundancia en las ciudades.

Por supuesto que los fenómenos son muchos más complejos, y que las comparaciones entre países no đeben tomarse sino como ilustración, pero todo esto representa un ingente desperdicio de potenclal humano en la América Latina, que se agrega al mal aprovechamiento de la tierra y de la capacidad productiva de la industria y los servicios básicos. Pero hay algo talvez más inquietante, y es que esta falta de oportunidades afecta a las nuevas generaciones que se van asomando 


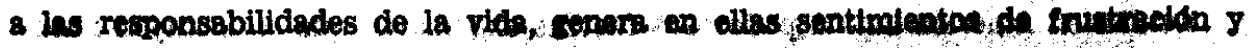

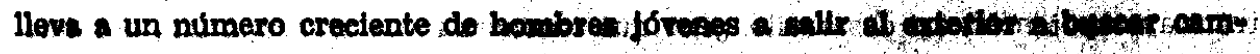

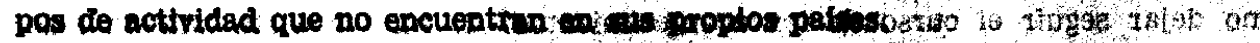

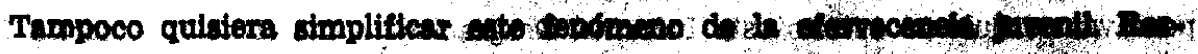

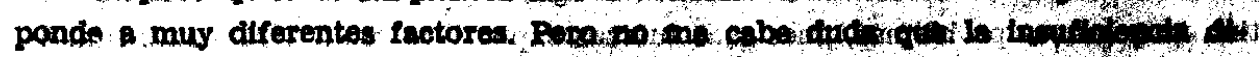

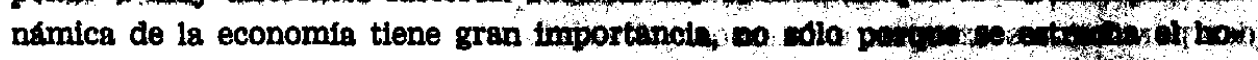

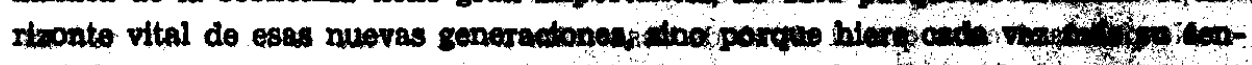

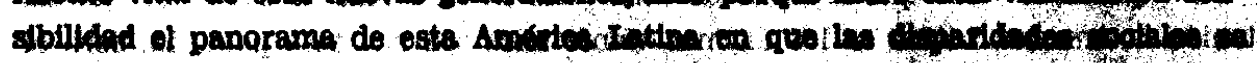

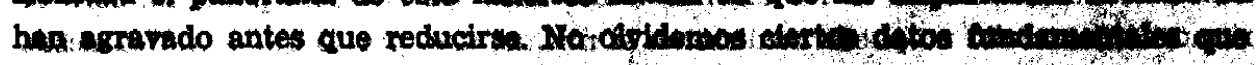

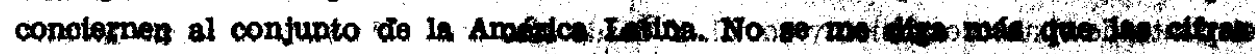

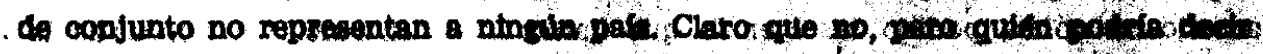

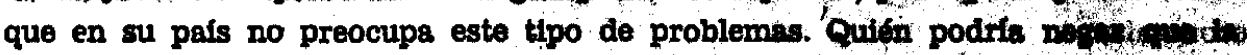

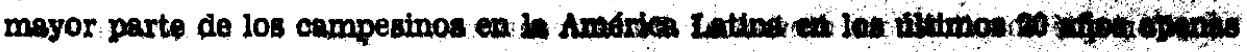

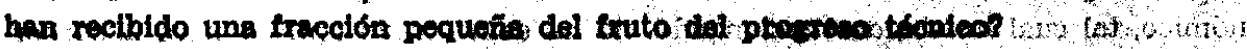

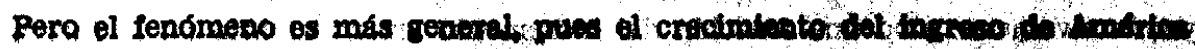

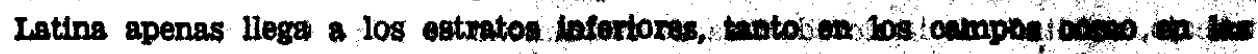

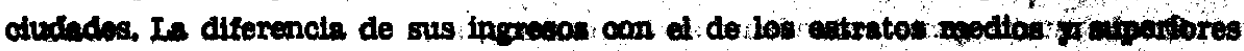

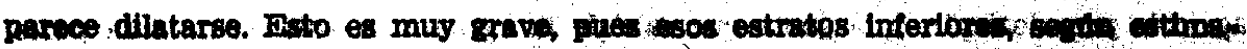

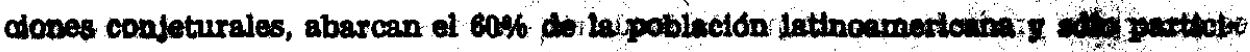

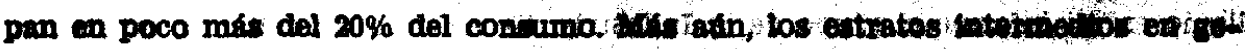
nersl dictan mucho de haber aorecentedo si ingreso, en relacion no teto a tuse lestitions espiraciones de bienestais thio al potencial do la Amorica Lattina

Quisiera dirigirme ahora a los industriales de la América Latina y preguntarios si puoden confiar en que la sustitudida déumportaciones lós va a seguir oivedendo un mercado suficiente como ex otros tiempon, y si no creen que ba llogado a momento de servir ademís a otro mareado que aquel que formó con 61 vacto que dejaban las importaciones. ¿Por qué no lanzarse a un mercado inthttor, a wa nueva trontera, ess nueva y promisara tronters de las masas rezagadar? Hay allf

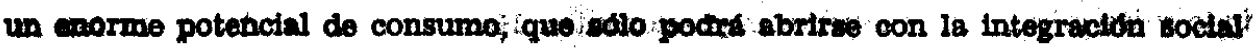
do las mases rezagadas en el campo y en las cludades de la América Itatin.

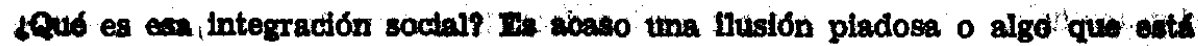

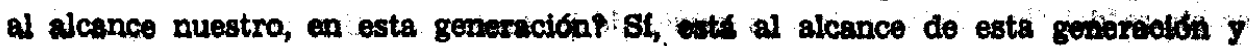

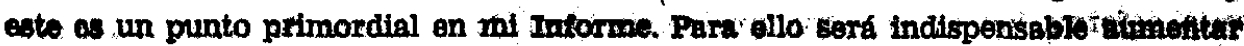
el producto medio por hombre en la agstcultura, por el mejor aprovechaminato

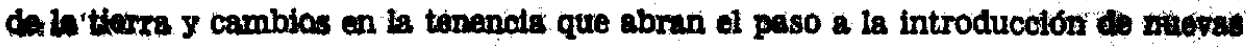
tocnolorias.

Pero no nos hagamos tlusiones, cuanto urids aumente el produoto por hombre, tanto mús intenso sera el drodo de gento de la agricultura. Esa gente tiene

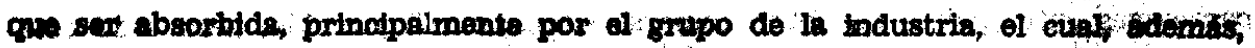

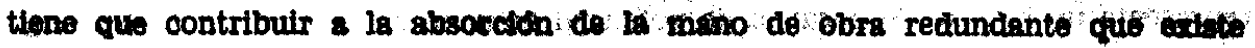
en las cludades.

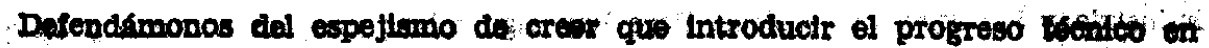

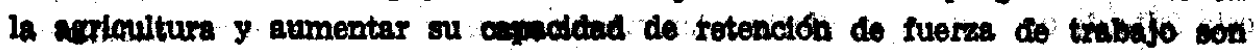


objetivos compatibles. No lo han sido historicamente, ni lo seran en el futuro salvo en casos circunstanciales. ¿Cómo acrecentar en consecuencia el poder de absorción de la industria? Esto es parte del problema general del desarrollo. Es indispensable en la América Latina elevar el ritmo de desarrollo. Hay paises que ya lo han hecho, y si bien dista mucho de ser suficiente, ello demuestra la posibilidad' de hacerlo. Pero no cabe ocultar que esto no es tarea fácil. La América Latina necesita cumplir un esfuerzo extraordinario de acumulación de capital, que tiene que hacerse fundamentalmente con sus propios recursos y tambien un extraordinario esfuerzo de comercio exterior.

$\mathbf{Y}$ aquí entro a un punto crucial de mi Informe. ¿Qué acumulación de capital y qué exigencias de comercio exterior tendrán que cumplirse para que la América Latina pueda afrontar con eficacia el problema de la insuficiencia dinámica de su economía? Es lo que quisiera decirles a ustedes ahora. Para ponerlo brevemente, esas exigencias imponen alcanzar una tasa mínima de crecimiento de $8 \%$ en el conjunto de la América Latina, en algunos países más, en otros menos, segun sus peculiares condiciones y problemas. Por supuesto que una meta así no podrá alcanzarse súbitamente. Por eso en mi Informe he hecho un planteamiento en que se pueda llegar a ese ritmo durante este decenio. Ese ritmo de desarrollo no responde a una mera cuestión de preferencias. ¿Por qué no se propone otro ritmo? Pues por la sencilla razón de que en la América Latina una tasa inferior no permitiría afrontar eficazmente el problema de la insuficiencia dinámica.

Ese ritmo de $8 \%$ a alcanzar en 10 años sólo permitiría detener el proceso de deformación ocupacional. Sería necesario mantener después ese ritmo del $8 \%$ durante otros 10 años para invertir ese proceso y aproximarse a una distribución más adecuada de la fuerza de trabajo, similar a la que hoy tienén México y la Argentina, o sea que el $\mathbf{4 0} \%$ de esta fuerza fuera de la agricultura, se ocupe en el grupo de la industria.

Estoy plenamente consciente de las considerables dificultades tanto internas como externas que se presentan para alcanzar estas metas. Veamos primero las de comercio exterior. Por razones que se explican en el Informe, las importaciones tenderian a crecer con un ritmo más elevado que el producto, o sea a más de un $8 \%$ por affo. De otro lado, serfa muy optimista pensar que las exportaciones habituales crezcan con una tasa semejante. Uno de los imperativos más terminantes que se desprenden del Informe es que habrá que hacer un esfuerzo extraordinario para desenvolver nuevas exportaciones de carácter industrial, lo que exigirá una politica firme y sostenida. Ahora bien, aún cuando la América Latina pudiera alcanzar las tasas más altas de los países que más éxito han tenido en el mundo en la exportación de manufactura en las ültimas đécadas, le quedaría aún una brecha relativamente grande y aproximadamente el $3 \%$ de la tasa de crecimiento del $8 \%$, a cubrir de otra manera.

En el Informe se llega a la conclusión de que este vacío sólo puede llenarse en pequeña parte con recursos financieros internacionales. Un estuerzo decisivo tendrá que hacerse inevitablemente mediante la sustitución de importaciones. 
Aqui se plantea un punto de primordial importancia. Si vamode atandinga

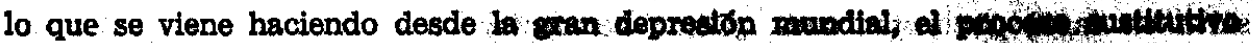

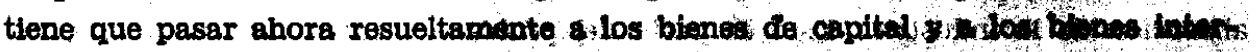

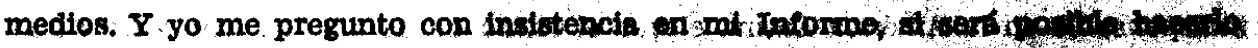

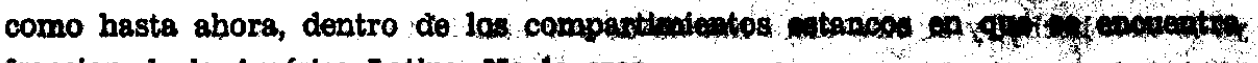

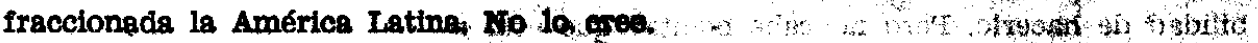

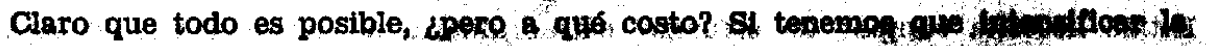

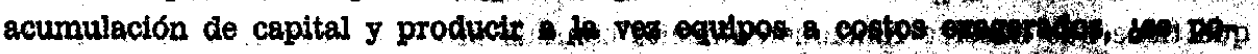

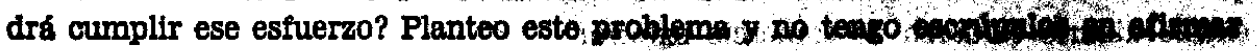

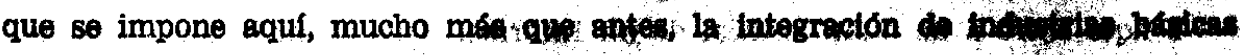

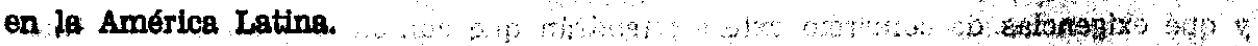

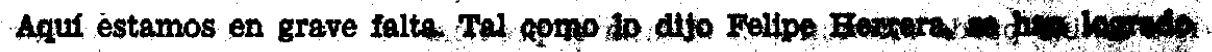

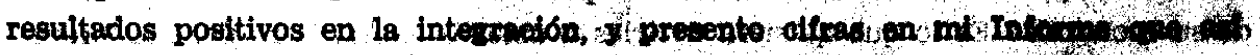

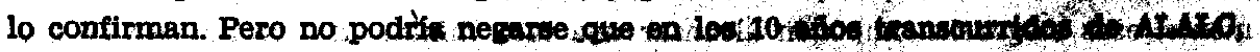

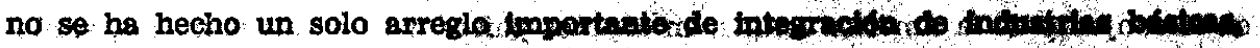

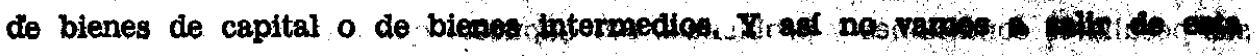
crisis estructural de la Amério Latina

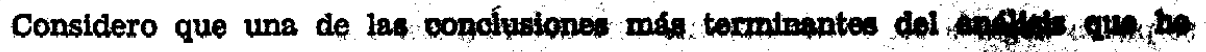

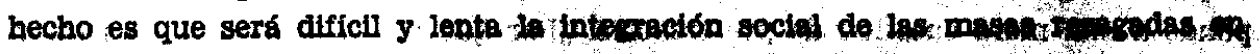

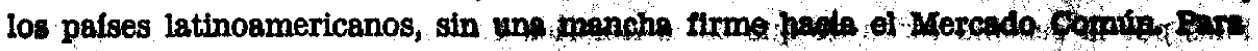

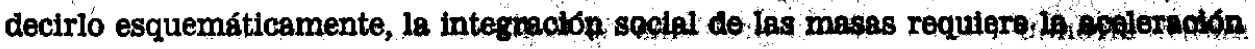
del ritmo de desarrollo. Esto a vu exige yencer el estrangulamiento eforlor de la economía y esto implica expartar productos industriales, y por mas optimista que se sẹa con respecto $\theta_{j}$ la exportación al resto del mundo, es indispensable aumentar sobre todo la exportación de blenes de capital y de blenge intart medios entre los palses latinoamerteanos bajo un Mercado Común en formación. No se haga ilusiones la América Latina. No se podrá acolerar e] desarrollo çon. fuerte sentido social sin la cohesión de las oconomias latinoamericanas Pero entendámonos bien. La integración no pugde ser un instrumento para qup sa daterrollen los países más grandes, dojando la zaga los modianos y pequanos, sino para que todos compartan las ventajas del progreso técnico y de la industrlalien ción. Aquí también se necesita yma política consciente y deliberada como pare el desarrollo interno.

Ahora bien, estos programas do intensificación de las exportaciones ygn a den morar en rendir todos sus trutos. Mientras tanto, para emprender 10 acelezación de su ritmo de desarrollo, la América Latina necestta importar, sobre toco blenes do capital, y es aquil donde reo la necesidad o la conveniencia de la aportación de recursos financieros internaciopales, para adquirir esos bienes que no podemos producir, ni ađquirir en un comignzo con nuestras exportaciones. Y agul eptro en. un aspecto importantísimo del planteamiento del Informe. La necesidad Ao una aportación masiva de tales recursos, jizada a muy juiciosos planes de desarrollo económico y social, para elevar con celerided el producto en un nimero carto de anos, sobre todo aprovechando la capacidad ociosa de la economia latinpempriann 
Recordemos que nuestras economías, cuando atraviesan por periodos de bonanza en las exportaciones, son capaces de aumentar rápidamente su ritmo decreclmiento. Esta reacción no sería posible si no existiera capacidad ociosa. Claro que cuando la situación del comercio exterior se torna nuevamente precaria, vuelve a quedar un margen considerable de capacidad sin aprovechar. Pero el esfuerzo debe ser persistente, no sólo para aprovechar la capacidad ociosa, sino para aumentar la tasa de inversión.

En el Informe presento cifras que demuestran cómo podrian elevarse apreciablemente los recursos internos de inversión, frenando por un perfodo el incremento del consumo más que el consumo en si mismo, en los estratos superiores e intermedios de la colectividad. No así el de los inferiores, que está muy a la zaga y que tienen necesidades que atenderse perentoriamente. Por donde se ve la combinación de objetivos: acelerar el desarrollo e ir estrechando las disparidades sociales. Para que se tenga una medida de las dimensiones de este esfuerzo, el coeficiente de inversiones tendria que subir del $18 \%$ actual al $26 \%$ hacia fines del decenio, y la mayor parte del esfuerzo tiene que ser interno. Reltero que no estoy proponiendo una estrategia para cada país, sino llamar la atenctón sobre problemas que a todos interesan.

Es extraordinario el esfuerzo que debemos cumplir para pasar a un ritmo que vaya corrigiendo la insuficiencia dinámica. Esfuerzo que será tanto más difícil cuanto menos vigorosa y positiva sea la polftica de cooperación internacional. No puede decirse que haya habido verdadera política de cooperación internacional. Lo vengo diciendo đe años atrás y lo repito ahora. Medidas déblles, inconexas y con frecuencia contradictorias. Pero tampoco quisiera negar una serie de realizaciones positivas. EL BID es una de ellas. Pero no insisto sobre esto en mi Informe, no porque me haya cansado de decirlo, sino porque otros han tomado esta tarea.

Ahí está el Informe Pearson, que para mí tiene un mérito singular. El mérito de preconizar medidas exageradas, irresponsables $\theta$ irrealistas. ¿Cómo no voy a decirlo señores si asi fueron calificadas las mismas medidas preconizadas por UNCTAD desde 1964? Otro caso notable también es el Informe Peterson, que consicero constructivo. Confieso que mi entusiasmo por estos informes sería mayor si hubieran dado más relevancia a la iniciativa de los países en desarrollo, cuya inferioridad tecnológica y financiera es manifesta. A mi juicio es esencial que la inversión privada extranjera, sin desmedro de su legitimo afan de ganancia, contribuya a corregir progresivamente este estado de cosas, antes que perpetuarlo. Lo digo por tres razones principales, que explico en mi Informe. Primero, porque es necesario dar a los elementos dinámicos de la economía latinoamericana un papel fundamental en su desarollo. Segundo, por consideraciones de balance de pagos; y tercero, y no en último lugar por cierto, porque resortes fundamentales de la economía latinoamericana no podrían manejarse desde afuera. Yo atribuyo un papel importante a la inversión privada extranjera, sobre todo cuando trae tecnologías que no son todavía accesibles a la América Latina, lo cual seguira existiendo dada la dinámica de la innovación tecnológica. 
De todos modos, no creo que ta preocupación creciente en la Amedos satian

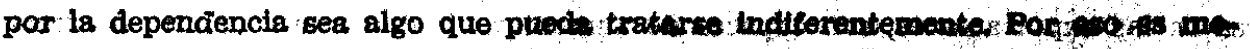

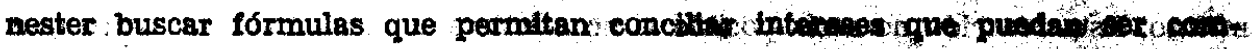

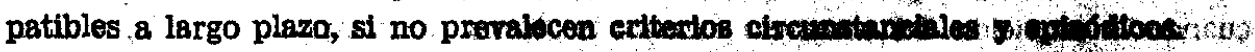

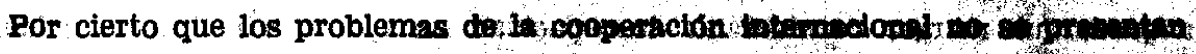

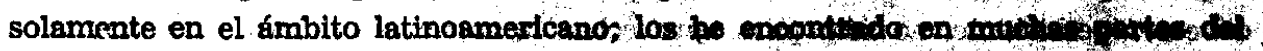

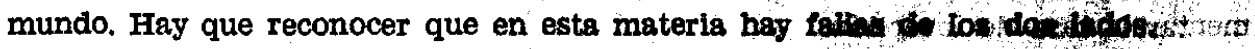

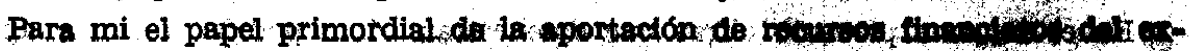

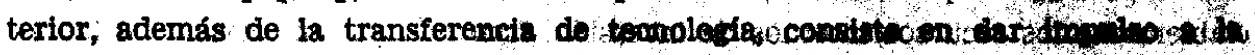

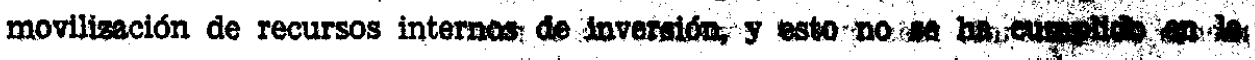

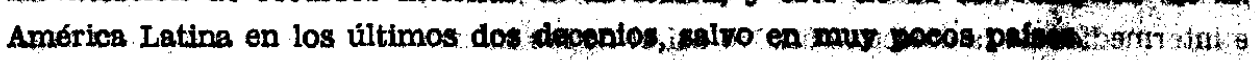

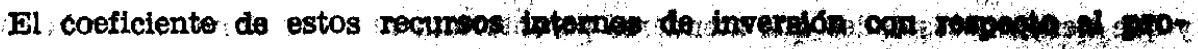

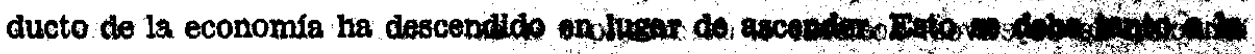

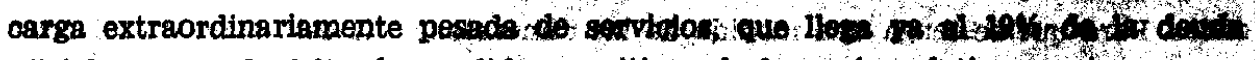

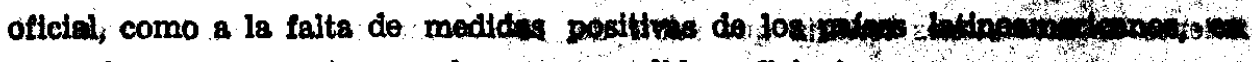

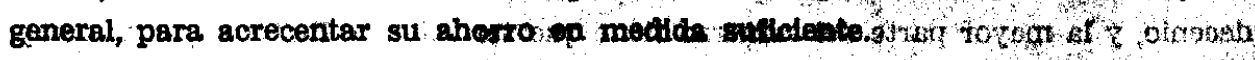

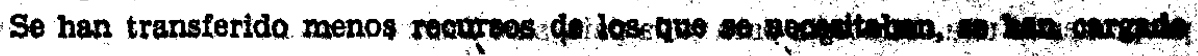

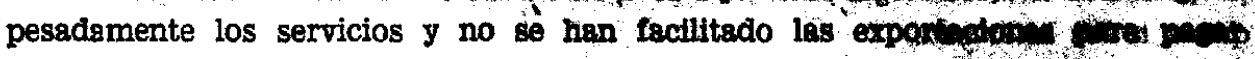

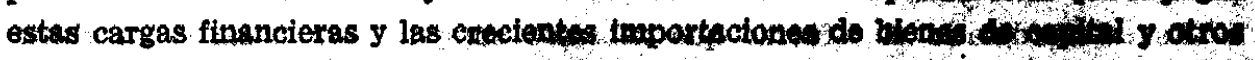

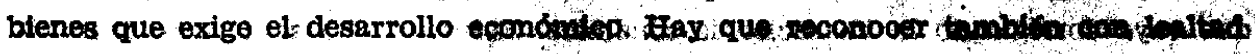
que, si bien son muy conocidas bes diftcultades que of recen los unpeadow dow paises desarrollados, los paises latinoamericavos a su vez han desperdictado oport. tunidedes de exportacion muy interesantes, is no ban emprendido con wicon la marchs hacla el Mercado Coming tque ha sida más bien débil y vacilantontm.

Estas experiencias tienen que tervir para extraer conclusiones positiva oon respecto al futuro. Es necesario, no solamente allviar la carga de ampithetiones e intereses como lo propone el Informo Pearson; sino evitar que en el outuro esta carga contribuya a agravar el estrangulemiento exterior do la economia to wo erea que la América Latina necestle uns cantidad desmesurade de recurvos linancieros. Ni la necesita, ni convendria que ta turlera, porque tiene qua masar riondamentalmente. su desarrollo en el esfuerzo nacional. Basta para demonturio is stguiente consideración. Las Nactonew Unidas han recomendado, principalmonte on UNCTAD, que los países desarrollados transteren recursos financierce a $10 \mathrm{n}$ paten en desarrollo por un equivalente del $1 \%$ de su producto bruto. Fi Informe Peasenat recoge esta sugestión parcialmente y sugtere que so llegue en forma gradual a esta meta en 1975. Pues bien, sl ast fuera, y la América Latina dispustern do wnea proporctón como la del pasado, que oseibe entre 15 y $20 \%$ del total de catoorre. cursos, ello sería suficiente para que con un gran esfuerzo nacional se putads liegar. a fines de este decenio y mantener despues un ritmo de desarrollo do $8 \%$ amm como se dijo anteriormente.

Digo y repito, un gran esfuerzo nocional. Fn mi Informe no the vacthde on calliflear a este esfuerzo de disctplina del desarrollo, disciplina en la scumulinotó de capital, en el comercio exterion,y también en el arte poistico del davatrollo,

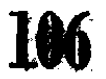


sea la aptitud para obrar consciente y deliberadamente sobre las fuerzas expansivas de la economía. Y para dar a la estrategia del desarrollo dimensiones nacionales, to cual supone la participación de todos los grupos sociales, y su determnación de seguir esa disciplina. Entiéndase bien: đisciplina del desarrollo, y no compulsión o regimentación del desarrollo.

Ya me he referido a los obstáculos externos; quisiera ahora mencionar los obstáculos internos, a los que el Informe dedica considerable atención. Llevar el ritmo de desarrollo al $8 \%$ es tarea muy difícil. Incorporar las masas campesinas rezagadas e integrarlas socialmente requiere aumentar el producto por hombre y yo quisiera que se reflexione si acaso es posible hacerlo $\sin$ transformaciones estructurales que permitan la introducción del progreso técnico. Me pregunto también sí serfa posible aprovechar el gran potencial de la industria y aumentar su productividad si ella sigue protegida por un muro de aranceles que sofocan la competencia y traban el eficaz funcionamiento de las fuerzas del mercado. $Y$ me pregunto por fin si el progreso técnico pođrá avanzar como tiene que avanzar si no se promueve una intensa movilidad social, no sólo a través de la educación general y la capacitación técnica, sino por la creación de oportunidades de trabajo. Nos complace mucho sefialar algunos progresos de la educación en América Latina, pero la insuficiencia dinámica de la economía explica que parte importante de esa gente que se capacita a un alto costo busque oportunidades en otras tierras, fenómeno más grave aún que la salida de capitales, que de suyo lo es un alto grado.

No habrá pues aceleración persistente del desarrollo si no se transforma la estructura económica y social, Al hacer estas afirmaciones no me guía dogmatismo alguno, pues creo no tenerlo. Porque es necesario ver este problema de la América Latina con gran independencia intelectual. Hablamos mucho de dependencia en la América Latina, y la hay y hay que vencerla. Pero todavía es fuerte el dominio intelectual dè ideas y concepciones que no corresponden a la realidad latinoamericana y a las de los países en desarrollo en general. Los adelantos científicos y tecnológicos, junto con sus grandes beneficios, traen problemas nuevos a la América Latina, que no se presentaron en la experfencia de los países hoy avanzados. Esos adelantos se presentan en verdad con muy fuertes contradicciones, como se advierte en la contradicción fundamental que existe entrs el crecimiento extraordinario de la población y la acumulación de capital. Crecimiento extraordinario que es el resultado de adelantos cientificos y tecnológicos y acumulación de capital que requiere ser cada vez mayor porque la técnica impone creciente intensidad de capital por hombre, al mismo tiempo que los medios de comunicacion de masas excitan constantemente a nuevas formas de consumo provenientes de los países más avanzados en países que tienen un poder de consumo muy inferior.

Las influencias adversas que gravitan sobre el comercio exterior latinoamericano son también consecuencias directas o indirectas del progreso técnico de los grandes centros. Superar esas contradicciones es tarea fundamental en la América 


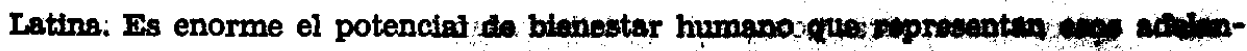

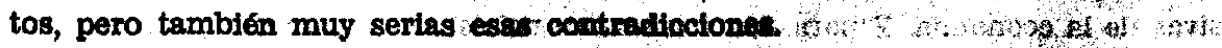

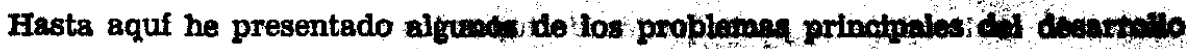

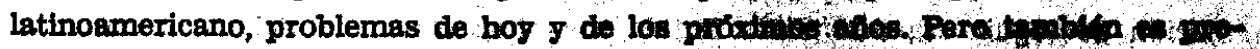

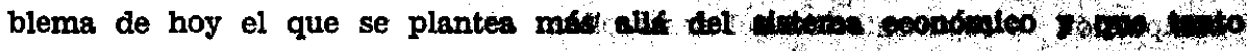

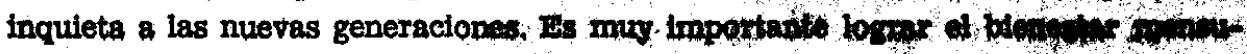

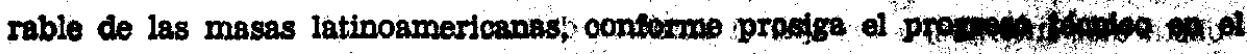

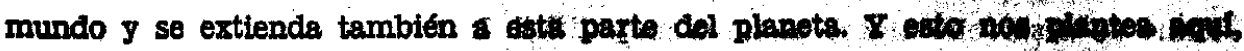

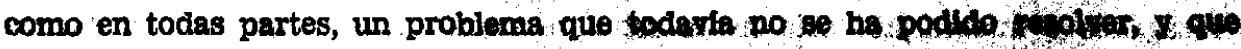

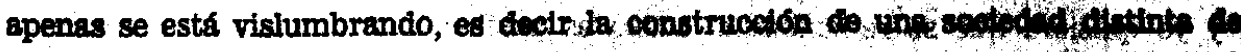

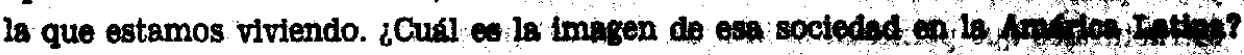

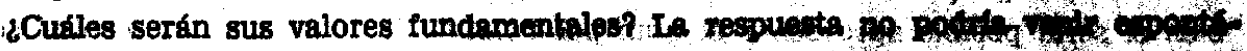

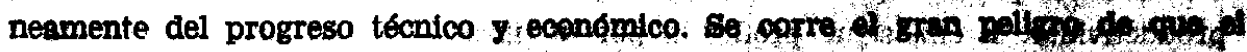

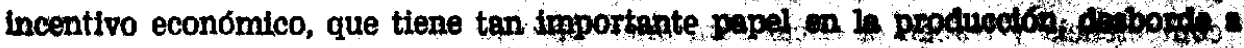

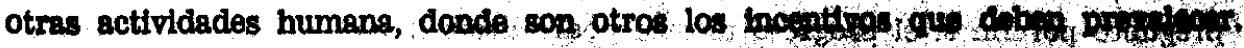

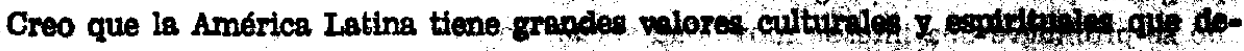

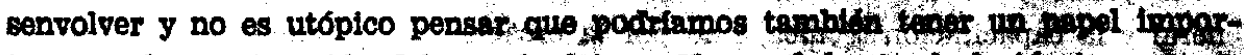

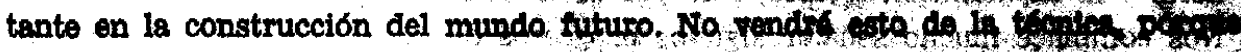

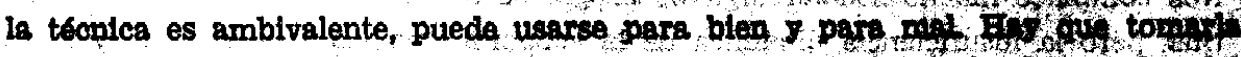

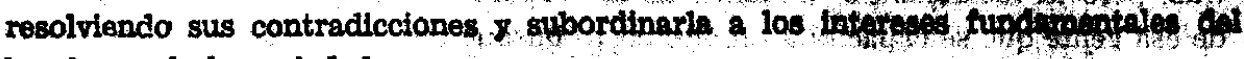
hombre y de la socledad.

No es posible sustraerse en todo esto a la emoción. La emoción que muqua grandes impulsos para construir, para hacer cosas nuevas, para afroptar figeos La emoción que nos lleva a fijar grandes objetivos y a luchar con resolinción para alcanzarlos. Pero éstos no podxán conseguirse sin racionalidad y previstón.

Reniégase a veces de la raciopalldad, porque se quiere destruir 10 que se considera malo, pero no podrá prescindirse de la racionalidad para construir de nuovo. Hago un llamado a la racionalidad y prevision, porque estamos a tiempo de obrar en forma deliberada sobre las tuerzas del desarrollo. Pero no tiene is Amoty Latina mucho tiempo que perder. Ni tampoco lo tiene el mundo desarpollado an formular una gran política de cooperación. In fin de cuentas, el problema de la integración soctal de las masas rezagadas en las dos terceras partes de fa humanidad, es un problema común, y resolverto es la gran eventura del desangollo.

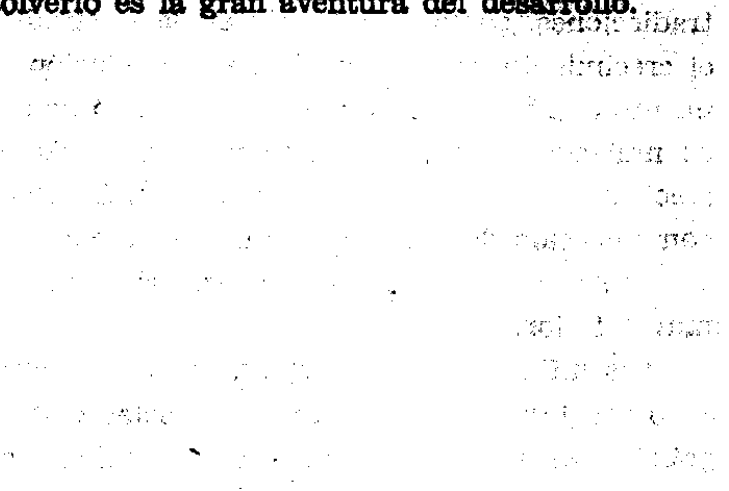

